\title{
MEASUREMENTS OF STRENGTH ON DAKSHIN GANGOTRI ICE SHELF IN EAST ANTARCTICA
}

\section{(Abstract)}

\author{
by
}

Satya S. Sharma

(Research and Development Establishment (Engineers), Dighi, Pune-411015, India)

\begin{abstract}
During the first wintering by Indian scientists in Antarctica, from December 1983 to February 1985, yearround measurements of the strength of the snow cover were carried out to a depth of $1 \mathrm{~m}$ on Dakshin Gangotri Ice Shelf in East Antarctica, around the Indian Antarctic research station Dakshin Gangotri $\left(70^{\circ} 05^{\prime} \mathrm{S}, 12^{\circ} \mathrm{E}\right)$. The measurements covered an area of $625 \mathrm{~km}^{2}$ around Dakshin Gangotri Station. Ten to 15 snow-hardness profiles per month were taken at different locations, using a Swiss ramsonde, and the values of ram resistance so obtained at different depths were averaged for each profile at depth intervals of $15 \mathrm{~cm}$. These values were later tabulated and the minimum, maximum and average values obtained for each month were calculated. The values of ram resistance so obtained for each period were then used for determining unconfined compressive-strength profiles of the snow cover during different winter periods, using the correlation function given by Abele (1963).

Based on these values, the average unconfined compressive strengths of snow cover were calculated for different depths in the ranges $0-30 \mathrm{~cm}, 0-45 \mathrm{~cm}, 0-60 \mathrm{~cm}$,
\end{abstract}

$45-100 \mathrm{~cm}, 60-100 \mathrm{~cm}$, and $75-100 \mathrm{~cm}$. Preliminary results show that the snow cover below $45 \mathrm{~cm}$ generally has high strength throughout the year, whereas the strength of the snow cover from 0 to $45 \mathrm{~cm}$ varies greatly with the time of year. This layer from 0 to $45 \mathrm{~cm}$ shows a general increase in strength from January to September, with peak values occurring between June and September. Strength decreases gradually from October to December, which is the warm period in Antarctica.

The hardness-profile values obtained by ramsonde, when duly converted into unconfined compressive strength, give a fair indication of trafficability of wheeled and tracked vehicles at different times of the year on the ice shelf. They also indicate the load-bearing capacity of the surface snow for landing light- to medium-weight aircraft.

\section{REFERENCE}

Abele, G. 1963. A correlation of unconfined compressive strength and ram hardness of processed snow. CRREL Tech Rep., 85. 